\title{
Visualization Performance Through Simulation Based Learning
}

\author{
Thomas E. Doyle ${ }^{I}$, David Musson ${ }^{2}$, and Jon-Michael J. Booth ${ }^{l}$ \\ ${ }^{1}$ Faculty of Engineering, Department of Electrical and Computer Engineering \& Engineering 1 Program \\ ${ }^{2}$ Faculty of Health Science, Center for Simulation Based Learning \\ McMaster University, Hamilton, Ontario, Canada \\ doylet@,musson@,boothjj@mcmaster.ca
}

\begin{abstract}
The skill of visualization is fundamental to the teaching and learning of engineering design and graphics. Implicit in any skill is the ability to improve with training and practice. This study examines visualization performance using three teaching modalities of a Freshmen Design and Graphics course: 1) Traditional, 2) Project based Dissection, and 3) Simulation based Design. The first and second modalities focused assessment on the part/assembly form, whereas the third modality transitioned the outcome expectations to understanding and function of mechanism design. A shift of focus from Traditional (Form) to Simulation (Function) was expected to positively effect visualization performance. Analogously, medical education and practice also require visualization and high-fidelity simulation has provided numerous positive outcomes for the practice of medicine. Comparison of a random population of 375 from each year indicated a decline in the average visualization scores. Further analysis revealed that highest 100 and 250 exam score populations show improvement in average scores with consistent variance. This paper will examine simulation based learning in medicine and engineering, present our findings on the comparison between teaching modalities, and discuss the reasons for the unexpected bifurcation of results.
\end{abstract}

Keywords: visualization, design, graphics, high-fidelity simulation, competency based outcomes, graduate attributes, cornerstone project

\section{INTRODUCTION}

The Engineering Design and Graphics course has dramatically changed to keep pace with the expectation of the practicing engineer. These changes have been the result of both technology and philosophy [1-4]. Mastery of slide-rule and t-square has been replaced with digital computation and computer aided design tools. Some may argue that adoption of such tools is an abdication of the responsibility to teach fundamentals. Alternatively, others would argue that omission of such tools places a young engineer at disadvantage. The authors believe that a balance can be achieved that not only addresses both arguments, but also provides the student unique insight, increased engagement, and an improved educational experience.

\subsection{Motivation}

Common feedback from freshmen students studying Engineering Design and Graphics (EDG) is that they do not possess the ability to visualize and thus cannot succeed in such a course. In a freshmen EDG course, few students have experience with the design process and fewer still have used CAD software. This general lack of background greatly explains why the traditional teaching process is often one of demonstration; however, it is this demonstration that may explain why students can adequately perform in the course but still profess to have no visualization capability. Additionally, even the students that have mastered the material in a traditional EDG course may not have an understanding of the parts and assemblies that they are modelling.

To address these issues, McMaster Engineering implemented a freshmen dissection project as a Cornerstone project into the first year EDG course. Examples of the dissection complexity were disposable cameras, cordless screwdrivers, CDROMs, floppy drives, etc. Teams of three would dissect and solid model the complete product for final presentation and assessment of their work. The expectation was team dissection would provide immediate visual verification of solid models, thereby helping students to visualize individual parts and complex assemblies. The instructor observed that this teaching modality improved engagement, however, it did not truly expose the students to a design process, nor did it significantly improve the class' understanding of how mechanical devices work. We believe that this result was directly tied to assessment, which was based on the form.

In a reimagining of the EDG course, emphasis was placed on balancing the design $v s$. the graphics. A primary challenge in addressing this balance was introducing a design problem in first year, particularly in first term of a common program. The Cornerstone project 
approach provides similar experience as a senior Capstone project, except the design problem is not open ended. The Cornerstone project provides a framework to shift the content and assessment focus of an EDG course from form to function and design.

Increasing class sizes, limited time, finite resources, and academic integrity must all be given consideration. For our design project to be successful it had to be grounded in theory, easily scalable, offer iterative testing, consider the requirements to facilitate design function assessment, and be sufficiently modifiable to ensure the large number of groups were working on different problems. While hardware solutions were considered, they presented challenges in scalability, testing, assessment, and academic integrity. A multi-domain, symbolic modelling and simulation software application was selected as a design iteration platform because it permitted students to import their solid model designs for three-dimensional interaction of a working model for virtual measurement, verification of hand calculations, and validation of target specifications.

Implicit in the usage of a simulation platform is the building of experience from often abstract and unfamiliar concepts. This lack of experience in a first year class is often cited as an impediment to introducing design to freshmen; however, the simulation can be designed to limit problem scope and to provide scaffolding to support the student in their design process.

Peripheral to the course design was the new Canadian Engineering Accreditation based upon graduate attributes and competency-based outcomes assessment. This type of assessment is similar to how medical students are evaluated and may provide some guidance for our own teaching methods and accreditation standards. One such teaching method that has multi-faceted success is the use of high-fidelity simulation for medical education.

\subsection{Literature Review}

Development of the McMaster Engineering 1 Cornerstone dissection and design projects may be found in references [5-7].

Project based learning (PjBL), not to be confused with Problem based learning (PBL), literature demonstrates an increasing international adoption of $\mathrm{PjBL}$ for engineering education [8]. However, surveys of faculty have found resistance in implementing $\mathrm{PjBL}$ until the efficacy of the method is proven [8]. The authors believe that studies, such as this paper, will help guide the use of $\mathrm{PjBL}$ in a wider number of engineering topics.
Table 1: EDG course structure and modality for 2006, 2009, and 2011.

\begin{tabular}{|c|c|c|c|}
\hline $\begin{array}{c}\text { Course } \\
\text { Properties }\end{array}$ & 2006 & 2009 & 2011 \\
\hline Modality & Traditional & Project - Dissection & Project - Simulation \\
\hline Topics & $\begin{array}{ll}\cdot & \text { Solid Modeling } \\
& \text { CAD } \\
\cdot & \text { Hand Sketching } \\
\cdot & \text { Engineering } \\
& \text { Drawings }\end{array}$ & $\begin{array}{ll} & \text { Solid Modeling CAD } \\
\cdot & \text { Hand Sketching } \\
\text { Engineering } \\
\text { - Drawings } \\
\text { - } & \text { Dissection Project } \\
& \text { Course Competition }\end{array}$ & $\begin{array}{ll}\text { - } & \text { Solid Modeling CAD } \\
\text { - } & \text { Hand Sketching } \\
\text { - } & \text { Mechaninisms Drawings } \\
\text { - Trains } \\
\text { - } \\
\text { Directed Dissection } \\
\text { Simulation Based } \\
\text { Design Project } \\
\text { - Course Competition }\end{array}$ \\
\hline $\begin{array}{c}\text { Year 1 } \\
\text { Enrolment }\end{array}$ & 857 & 1083 & 1304 \\
\hline Sections & 8 & 8 & 4 \\
\hline Final Exam & $2 \mathrm{~h}$ & $2 \mathrm{~h}$ & $3 \mathrm{~h}$ \\
\hline $\begin{array}{c}\text { Final Exam } \\
\text { Content }\end{array}$ & $\begin{array}{ll}\cdot & \begin{array}{l}\text { Multiple Choice } \\
\text { (visualization) }\end{array} \\
\cdot & \text { Isometric sketch } \\
\text { - } & \text { Multiview } \\
\text { sketch }\end{array}$ & $\begin{array}{ll}\cdot & \begin{array}{l}\text { Multiple Choice } \\
\text { (visualization) }\end{array} \\
\text { - } & \text { Isometric sketch } \\
\text { - } & \text { Multiview sketch }\end{array}$ & $\begin{array}{ll}\cdot & \text { Multiple Choice } \\
\text { (visualization) } \\
\text { - Multiple Choice (gear } \\
\text { train design) } \\
\text { - } \\
\text { Isometric sketch } \\
\text { Multiview sketch }\end{array}$ \\
\hline Instructors & Doyle/Elkott & Doyle/Cheng & Doyle \\
\hline
\end{tabular}

The simulation based learning literature is heavily based in medical education and assessment $[9,10]$. While not as extensive, there are a number of studies that examine the use of simulation based learning in engineering education $[1,11,12]$.

Cölln's paper on visual perception found that performance was improved when manipulating threedimensional CAD vs. static three-dimensional CAD or two-dimensional engineering drawings [13]. This result supports the hypothesis that simulation based learning using interactive three-dimensional models will improve visualization performance.

\subsection{Problem Definition}

Analyzed the visualization performance of freshmen engineering students across three modalities of teaching the EDG course (Table-1 outlines the EDG course properties for 2006, 2009, and 2011). Teaching modalities considered:

1. Traditional (CAD and sketching),

2. PjBL - Dissection (CAD, sketching, and group dissection-modelling project), and

3. PjBL - Simulation (CAD, sketching, and group design-test project).

\subsection{Selected Methodology}

The selected methodology examined student performance on two standard visualization types: isometric and mutiview sketches. The mean of aggregate score $($ isometric + multiview $=$ score $/ 57$ ) taken from final examinations was used for performance comparison.

Two data sets are evaluated: 
1. Data set 1 - random selection of 375 student aggregate scores from each of 2006, 2009, and 2011.

2. Data set 2 - exam scores are ordered for the highest 100 and lowest 100 student aggregate scores from each of 2006, 2009, and 2011

Exam questions are chosen for similar complexity and graded using the same rubric. Population mean and variance of aggregate scores are compared across modalities for statistical significance.

\subsection{Significance of Results Obtained}

The results are highly significant to the design educators considering the efficacy of either $\mathrm{PjBL}$ or Simulation based learning. The data for whole class performance demonstrated that both $\mathrm{PjBL}$ - Dissection and PjBL- Simulation had negative effects on visualization performance; however, deeper analysis presents a bifurcation of that performance.

\section{SIMULATION-BASED LEARNING}

Simulation may be considered a form of experiential learning. Quite often though simulation is considered confined to only software applications and that they extend no further than the desktop. The simulation is not a singular application or a piece of hardware, it is the collective of the elements that creates the immersion and experience.

\subsection{Simulation in Medical Education}

Simulation, as an educational modality, has been used in medical education for many years, and technological advances in materials science and IT have stimulated a dramatic rise in the use of high fidelity simulation over the past decade. The first widespread use of simulation in medical education can be traced to the development of the standardized (simulated) patient. First developed by. Howard Barrows in 1963 at the University of Southern California, standardized patients consisted of actors who were trained to portray specific medical conditions for the purpose of teaching medical students in history taking and physical examination [14]. The use of standardized patients to teach these skills has now become widespread and the use of these resources can be found in virtually all medical schools in Canada and abroad in 2012. Studies have shown that performance assessments conducted using standardized patients are a reliable predictor of physician interactions with actual patients [15].

Anatomic models are a second simulation modality that is frequently used in medical education. Also termed

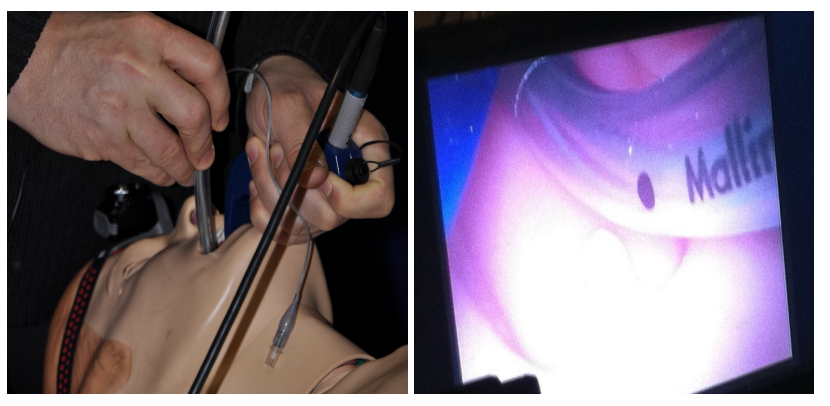

Fig. 1: Example of Simulation Based Learning in Medical education. On the left a SimMan3G is being used for an intubation during a high fidelity simulation. On the right are live images from the video laryngoscope showing the student an anatomically correct air passageway.

partial task trainers, these devices are used to teach and evaluate specific procedural skills. Examples of such devices include head and neck models with anatomically accurate representations of the human oropharynx, used to train airway management skills; upper limb models with latex skin and subcutaneous veins to teach intravenous needle insertion; and ultrasound capable head and neck models designed to facilitate ultrasound guided central line insertion procedures. These models pose significant advantages over didactic-only or textbook based learning in that they facilitate the learning and visualization of three-dimensional anatomy, psychomotor skill rehearsal, algorithm and procedural skill execution, and supporting activities such as the practice of aseptic techniques. More advanced procedural trainers integrate such technologies as virtual reality simulation and haptic feedback, such as is found any number of currently available laparoscopic surgical skills. Many studies have demonstrated the efficacy of using such procedural skills trainers in the acquisition of new and complex technical skills $[16,17]$.

In the past decade, hi-fidelity full-body simulators have assumed an increasingly prominent role in advanced medical education. These devices replicate the full human body, and have advanced capabilities in addition to basic anatomic modeling. Such capabilities can include chest movement, airway pathology (compliance and resistance modeling), lung sounds, heart sounds, airway management techniques, pupillary responsiveness, and so on. Although it is possible to use these devices to train specific procedural skills, the majority of educators are focusing more and more on interpersonal, teamwork, communication, and leadership skills [18]. In particular these platforms are used to train and assess cardiac resuscitation, trauma resuscitation, and surgical team performance.

The key features of simulation-based learning that set it apart from more traditional models of education are that such learning appears to address more complex skill sets, 
behavioral competencies, higher order cognitive functioning (such as mutual performance monitoring, task delegation, multitasking, and dynamic treatment algorithm application). Visualization of optimal performance and team management strategies becomes possible when trainees are given the opportunity to put semantic knowledge into practice. More traditional models of education have relied on the acquisition of descriptive (or declarative) knowledge and on paper and pencil tests to assess that knowledge. Development of procedural knowledge was largely achieved at the bedside, sometimes to the detriment of the patient. Simulation-based learning appears to fill the gap between learning from the textbook and practicing on real people.

\subsection{Simulation as a Component of EDG}

For the PjBL - Simulation modality students employ MapleSim, a symbolic modelling and visualization software package, to import their solid modelling Autodesk Inventor CAD designs for immediate verification and validation.
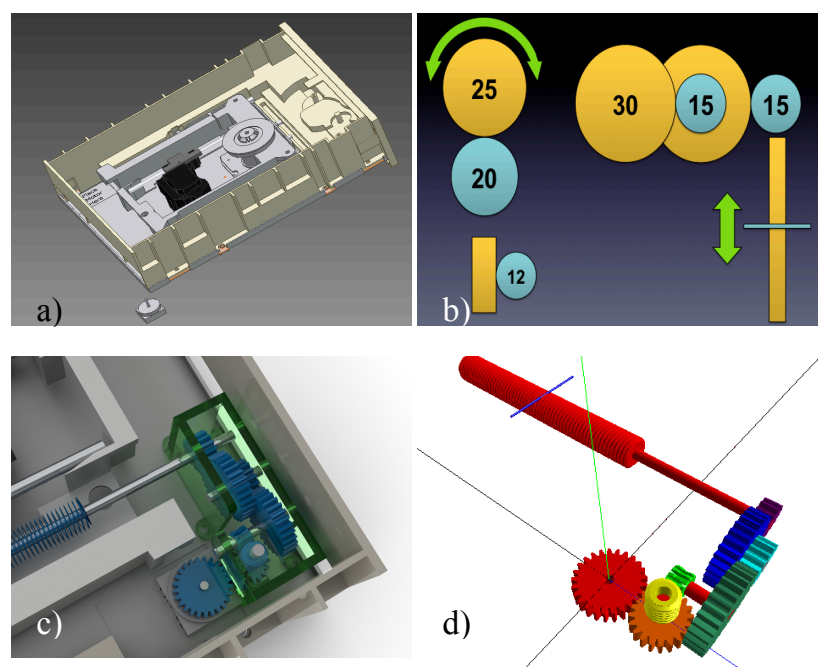

Fig. 2: Design Process in McMaster EDG PjBL - Design Project: a) students are provided a solid model of a real product that must be retrofitted, b) example of hand calculations using simplified gear design (student submission), c) solid model based on hand calculations (student submission), and d) solid model imported into three-dimensional simulation of gear train function (student submission).

Starting in week six of the twelve week McMaster EDG course, the focus begins to shift to the consideration of function and design. The project is framed as a retrofit of an existing gear train that is no longer available. Every design team ( 3 members) is assigned a unique input speed for their device motor. Position and orientation of the motor is chosen by the instructor. Design groups must then set out to calculate the appropriate gear train to translate their given input parameters to the original device output. In the case of the example shown in Fig. 2, students were designing a retrofit gear train to meet the output design specification of $0.1625 \mathrm{~m} / \mathrm{s}$ for a CDROM read-head.

Students follow the complete Dym and Little design cycle [19] and have completed hand calculations before starting to model (CAD or simulation). There are no linkages between the solid modeler and the simulation modeler. Students import their calculated solid models into the system simulation modeler and test their design. Using provided simulation modules for pairs of spur and worm style gears student can focus on the incremental testing and verification of their designs. An unsuccessful test requires the students to return to their hand calculations - the software does not auto-generate optimal solutions. This simulation gives the freshman the opportunity to build design and troubleshooting experience; albeit in an ideal set of conditions.

This PjBL - Simulation modality provides students the ability to interact with their designs both spatially and functionally. Prior to the simulation component, the PjBL - Dissection modality concluded at twelve weeks with design groups having completed the modelling for one design that was only evaluated for form and never required iteration. As functionality was never tested, groups would often model the product to appear visually complete, but could never function.

\section{RESULTS}

\subsection{Data Set 1}

For a random selection of 375 scores from each modality, Fig. 3-a) presents box plots describing the median, the 25 th and 75 th percentiles, maximum and minimum, and outliers. The box notches allow the observer to compare medians; if the notches do not overlap then with $95 \%$ confidence the difference is statistically significant. Table 2 presents the mean and standard deviation across teaching modalities.

Table 2: Comparison of Mean and Standard Deviation Across Teaching Modalities $(\mathbf{n}=375)$.

\begin{tabular}{ccc}
\hline Year & Mean & Std. deviation \\
\hline 2006 & 42.1 & 6.9 \\
2009 & 36.9 & 7.3 \\
2011 & 33.4 & 10.6 \\
\hline
\end{tabular}


Data Set 1 results show a statistically significant decline in the aggregate visualization performance scores from 2006 to 2009 and from 2009 to 2011. An Analysis of Variance (ANOVA) was conducted comparing means for all three years, and the effect of YEAR was found to be highly significant $\left(\mathrm{F}_{1124,2}=114.2, \mathrm{p}<0.0001\right)$. Standard deviation increased slightly from 2006 to 2009, and markedly increased from 2009 to 2011. The score distribution from 2006 to 2009 was similar with lower mean in 2009. The 2011 score distribution had a much larger range than either 2006 or 2009

\subsection{Data Set 2}

Each modality data set was ranked by total exam score. The highest-100 and the lowest-100 ranked exam aggregate visualization scores were compared. Figures 3b) and 3-c) present box plots describing the median, the 25th and 75th percentiles, maximum and minimum, and outliers. Tables 3 and 4 present the mean and standard deviation across teaching modalities.

For the highest-100 ranked results, Data Set 2 presented a consistent standard deviation and similar distribution across modalities. The average aggregate visualization performance decreased from 2006 to 2009, but increased from 2009 to 2011.

For the lowest-100 ranked results, Data Set 2 presented a consistent increasing standard deviation across modalities. The score distribution range widened significantly in 2011. The average aggregate visualization performance decreased from 2006 to 2009, and again from 2009 to 2011.

Table 3: Comparison of Mean and Standard Deviation Across Teaching Modalities (highest ranked exam scores, $\mathbf{n}=\mathbf{1 0 0}$ )

\begin{tabular}{ccc}
\hline Year & Mean & Std. deviation \\
\hline 2006 & 48.7 & 3.6 \\
2009 & 44.8 & 3.6 \\
2011 & 47.2 & 3.6 \\
\hline
\end{tabular}

Table 4: Comparison of Mean and Standard Deviation Across Teaching Modalities (lowest ranked exam scores, $\mathbf{n}=\mathbf{1 0 0}$ )

\begin{tabular}{ccc}
\hline Year & Mean & Std. deviation \\
\hline 2006 & 36.2 & 4.1 \\
2009 & 27.9 & 5.7 \\
2011 & 19.2 & 6.9 \\
\hline
\end{tabular}
To further explore these data, the top 100 and top 250 bifurcation of populations. scoring students were identified, based on ranking
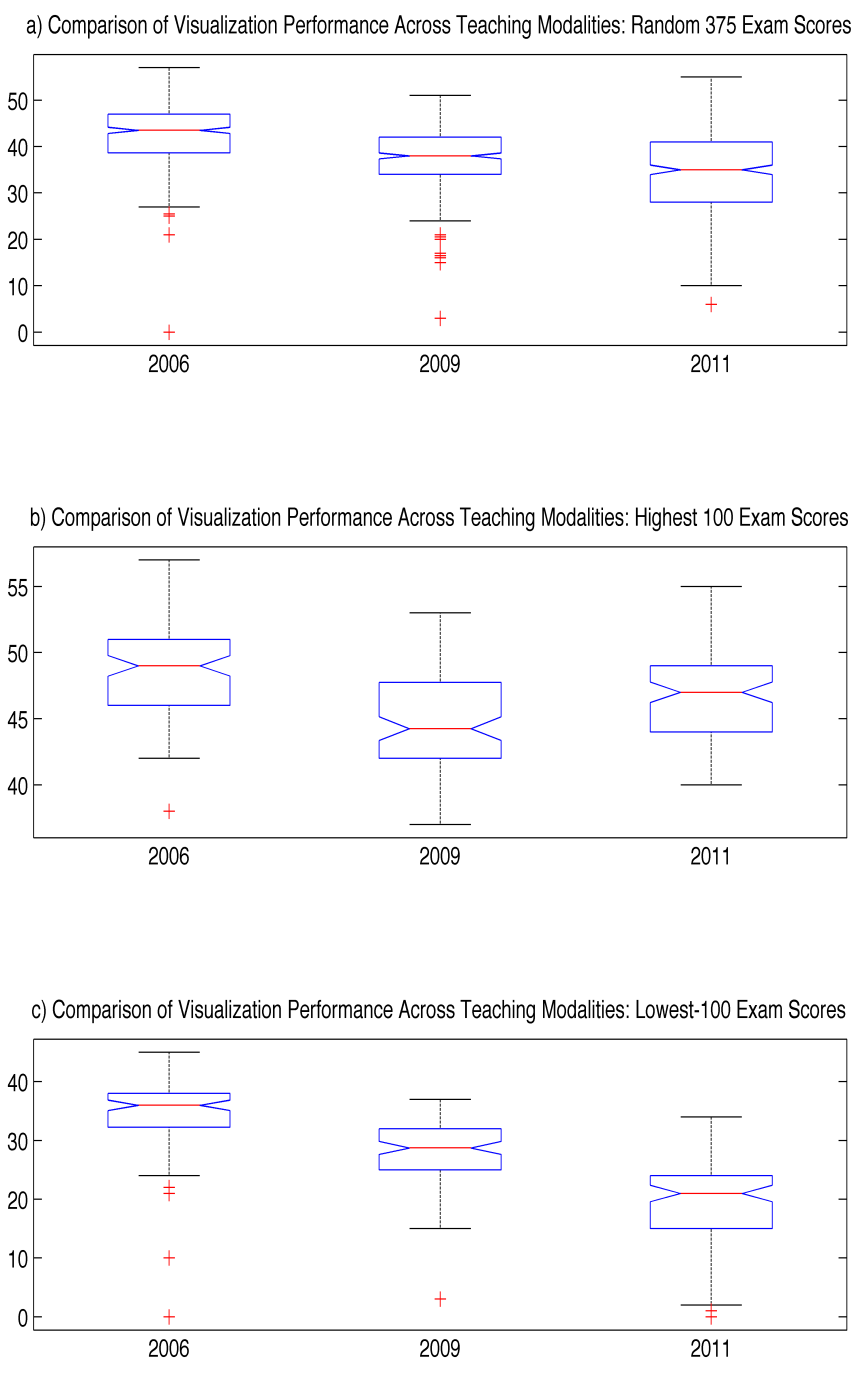

Fig. 3: Comparison of visualization performance across teaching modalities: a) random population of 375 from each modality, b) ranked highest 100 exam scores, and c) ranked lowest 100 exam scores.

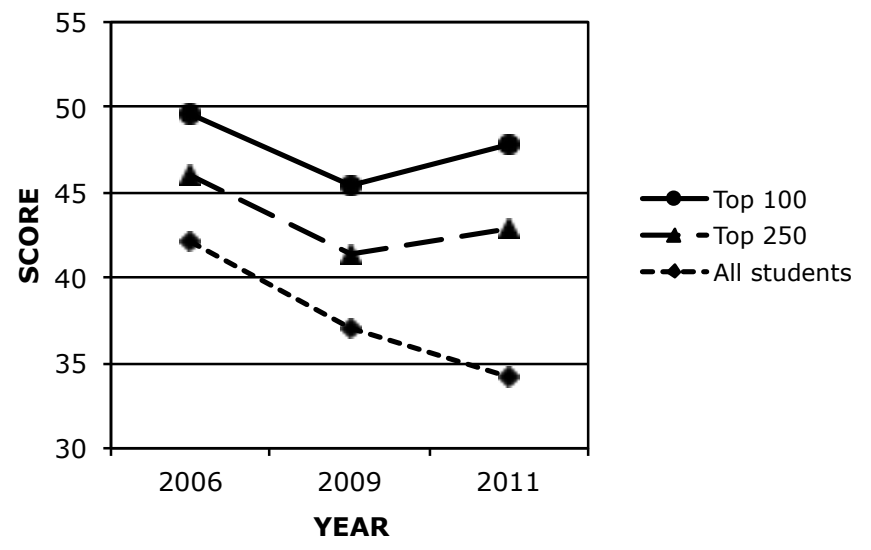

Fig. 4: Summary of results illustrating the unexpected 
aggregate of scores from the isometric and multi-view visualization components of the final examination. Means within all three groups (Top 100, Top 250, and All Students) were compared for years 2006, 2009, and 2011. These data are shown graphically in Fig. 4. Analyses of Variance (ANOVAs) were conducted for each of these three data sets, with YEAR as the grouping variable in each case. Results indicated a highly significant effect for YEAR in each of the Top $100\left(\mathrm{~F}_{299,2}=57.2, \mathrm{p}<0.001\right)$, Top $250 \quad\left(\mathrm{~F}_{749,2}=43.4, \quad \mathrm{p}<0.001\right)$, and total students $\left(\mathrm{F}_{1310,2}=96.3, \mathrm{p}<0.001\right)$ data sets.

\section{DISCUSSION}

Initial results from Data Set 1 indicated a decrease in visualization performance. Examination of Data Set 1 distribution warranted further investigation into the increased variance and wide range of scores. Data Set 1 was ranked by total exam score and partitioned into highest-100 and lowest-100. It was expected that the partitioned sets would present similar characteristics across modalities. The standard deviation and relative distribution of the highest-100 was consistent across modalities with improvement in visualization performance. The lowest-100 presented the opposite trend with decreasing performance, increasing variance, and wider distribution. Figure 4 illustrates this interesting and unexpected bifurcation. The analysis was performed again with the highest-250 final exam scores and the results were unchanged from the highest-100.

These results provide evidence that the simulation based learning has improved their visualization performance compared to a dissection project. While the absolute performance is lower that the traditional approach data, we may also consider the increase in course content, difficulty, and enrolment. While the results demonstrate that a population within the class is having difficulty, this study will assist in refining the course to help address this concern.

The authors have also considered that the results may be skewed as a result of an individual having sketching skills that are lower than his or her visualization ability. It is also possible that 2011 students allocated less exam time to performing the sketching due to increased content and complexity.

In Sept. 2012 the McMaster EDG course will be incorporating three-dimensional printers as a parallel modality for study. The ability to manufacture the designs may generally improve visualization performance, but particularly for the students struggling with visualization.
$\mathrm{PjBL}$ - Simulation is the best of the three modalities for the assessing competency based outcomes, or graduate attributes. Medical education literature presents a strong history of the efficacy of this modality.

\section{CONCLUSION}

This study has found that simulation based learning in engineering design and graphics has a positive impact on visualization performance for many students. Simulation based learning is an effective method of implementing project based learning and design education in engineering, partially in large freshman engineering courses. The presented approach is transferrable and could be readily adopted elsewhere. Finally, the measure of competency based outcomes is well suited to this modality.

\section{Acknowledgements}

The authors would like to acknowledge support from the Higher Education Quality Council of Ontario, MapleSoft, and Studica. The authors would also like to thank the Faculty of Engineering's Year 1 program and the Faculty of Health Science's Center for Simulation Based Learning at McMaster University.

\section{References}

[1] Butler, W. M., The Impact of Simulation-Based Learning in Aircraft Design on Aerospace Student Preparedness for Engineering Practice: A Mixed Methods Approach. Virginia Polytechnic Institute and State University, Doctoral Thesis, 2012, 223pp.

[2] Robertson, B. F., and Radcliffe, D. F., "Impact of CAD tools on creative problem solving in engineering design," Computer-Aided Design, 41(3), 136-146, 2009. doi:10.1016/j.cad.2008.06.007

[3] Sorby, S. A., "Education Research in Developing 3-D Spatial Skills for Engineering Students", International Journal of Science Education. Vol. 31, No. 3, 1 February 2009, pp. 459-480, 2009.

[4] Barr, R. E., Krueger, T. J., and Aanstoos, T. A., "The new digital engineering design and graphics process," Engineering Design Graphics Journal, 66(3), 2009.

[5] Doyle, T. E., Smith W. S., and Ieta, A., "Closing the design loop in freshman engineering," in Proc. of ASEE American Society for Engineering Education Annual Conference, (Vancouver, British Columbia, Canada, June 2011), 8 pp., 2011.

[6] Doyle, T. E., "Cornerstone design: product dissection in a common first-year engineering design and graphics course," in Proc. of ASEE American Society for Engineering 
Education Annual Conference, (Austin, Texas, USA, June 2009), 7 pp., 2009.

[7] Doyle, T. E., Baetz, B. W., and Lopes, B., "First-year engineering bicycle dissection as an introduction to sustainable design," in Proc. of the CDEN/C2E2 Sixth International Conference on Innovation and Practices in Engineering Design and Engineering Education, (Hamilton, Ontario, Canada, July 2009), 5 pp.,2009.

[8] Graham, R., UK Approaches to Engineering Project-Based Learning. Bernard M. Gordon-MIT Engineering Leadership Program, 2010, 44 pp.

[9] Stuart, G. E., and Drudi, L., "Medical education for exploration class missions - NASA aerospace medicine elective at the kennedy space centre," McGill J Med., 13(2): 55,2011

[10] LeBlanc, V. R., Manser, T., Weinger, M. B., Musson, D., Kutzin, J., and Howard, S. K., "The study of factors affecting human and systems performance in healthcare using simulation," Simulation in Healthcare, 6(7), 2011.

[11] Chung, G. K. W. K., Harmon, T. C., and Baker, E. L., "The impact of a simulation-based learning design project on student learning," IEEE Transactions on Education, 44(4), p390-398, 2001. doi:10.1109/13.965789

[12] de Jong, T., van Joolingen, W. R., Swaak, J., Veermans, K., Limbach, R., King, S., and Gureghian, D., "Self-directed learning in simulation-based discovery environments," Journal of Computer Assisted Learning, 14(3), p235-246, 1998. doi:10.1046/j.1365-2729.1998.143060.x
[13] Cölln, M., Kusch, K., Helmert, J., and Kohler, P., "Comparing two types of engineering visualizations: Taskrelated manipulations matter," Applied Ergonomics. 43, p. 48-56, 2011.

[14] Barrows, H., "An overview of the uses of standardized patients for teaching and evaluating clinical skills," Academic Medicine, 68(6), p. 443-453, 1993.

[15] Tamblyn, R. M., "Use of standardized patients in the assessment of medical practice," Canadian Medical Association Journal, 158(2), p.205-207, 1998.

[16] Aggarwal, R., Grantcharov, T., Eriksen, J. R., Blirup, D., Kristiansen, V. B., Funch-Jensen, P., and Darzi, A., "An evidence-based virtual reality training program for novice laparoscopic surgeons," Annals of Surgery, 244(2), p. 310314,2006

[17] Orzech, N., Palter, V., Richard N., Reznick, K., Aggarwal, R., and Grantcharov, T. P., "A comparison of 2 ex vivo training curricula for advanced laparoscopic skills: a randomized controlled trial," Annals of Surgery, 255(5), p.833-839, 2012.

[18] Musson D., and Helmreich, R., "Team training and resource management in health care: current issues and future directions," Harvard health Policy Review, 5(1), 2004.

[19] Dym, C., and Little, P., Engineering Design: A Project Based Introduction, Hoboken, NJ, USA, Wiley (3rd ed.), $352 \mathrm{pp}$. 